\section{BIOLOGICAL RESEARCH IN THE ARGENTINE}

A

NUMBER of reprints from La Revista de la Facultad de Agronomia y Veterinaria, 10, 111, November 1943 (Universidad de Buenos Aires; Facultad de Agronomía y Veterinaria) have recently been received.

F. Monrós has a paper with the title, "Algunos coleópteros de interés forestal observados en la Isla Victoria (Gobernación del Neuquen)". Observations conducted at the Victoria island of the National Park of Nahuel Huapi, during the months of January and February 1943, enabled the author to compile a list of Coleoptera which were detrimental to forest trees. A brief outline of the ecology of the island is given with the object of locating more easily the various species which are catalogued. About a dozen species are mentioned, and a list of the families found on the island is given, with the percentage of species corresponding to each one of these. Certain species which are abundant in other parts are not found on the island, and none of the Coleoptera on the island has been discovered in the surrounding regions. Aquatic or sub-aquatic Coleoptera were very seldom found, and terrestrial Micro-coleoptera were poorly represented. Some species fed on decayed organic matter, and $a$ few others lived on the flora. Other interesting information is supplied by the author, who has made a very exhaustive examination of the Coleoptera on the island.

José Vallega has a paper with the title "Razas fisiológicas de 'Puccinia graminis avenae' halladas en la Argentina", which deals with the above pest found especially in the central and northerm parts of the cereal region of the Argentine. Physiological races 3 and 7 were equally abundant and had the same geographical distribution. Experiments on resistance showed that, in general, oats cultivated in the Argentine and Uruguay were very susceptible to the two races of Puccinia, but among the foreign varieties the following were remarkable for their resistance : Richland, Rainbow, Iogold, Green Russian, Hawkeye, and a number of hybrids descended from them. In addition to the genus Avena, a number of grasses showed certain degrees of susceptibility; a list of these is given. The technique adopted for the investigation of the infection, powers of resistance, and various other matters relating to the investigation, were described in detail in a previous work published in 1940 .

In a paper with the title "Observaciones sobre la biología floral de Solanum chacoense Bitter", Enrique L. Ratera describes the results of his investigations on this species during the years 1935-42. Research was conducted at the field station of the Institute of Genetics of the Faculty of Agriculture and Veterinary Science of the University of Buenos Aires, where the species, which is self-fertilizing, flowered and fruited abundantly. Diagrams show the appearance of the flower in the early morning and at other times; the positions adopted towards evening and during the night favour self-pollination; the anthers mature simultaneously with the receptivity of the stigma. From numerous observations it appears that the duration of the flowers of the species is about 4-5 days, at least in the place where the experiments were conducted.

Juan B. Marchionatto has a paper with the title "La obra fitopatológica de L. Hauman en la Argen- tina" which deals with Prof. Hauman's researches, especially those of which the results were published during 1907-25. His work started in 1904 in the Instituto Superior de Agronomía y Veterinaria de Buenos Aires, which became later the Facultad de Agronomía y Veterinaria. Hauman's first results were published in collaboration with Juan A. Devoto in 1908, and were a prelude to a more important publication six years later under the title "Les parasites végétaux des plantes cultivées en Argentine et dans les regions limitrophes". As a supplementary work, which was indispensable for teaching purposes, a collection of phytopathological specimens was prepared; and it was found that a solution of copper formate preserved the colour of the green organisms as well as the vegetable structure. The most important of his studies was connected with the mutations of certain organisms in vegetables, a task on which he laboured for several years and which resulted in showing that Mucor stolonifer Erb. was responsible for the production of decaying matter in the potato, although other fungi and certain bacilli were capable of producing similar results under experimental conditions. A very important paper was published in 1913 in Ann. l'Inst. Pasteur (A 27, 501), with the title "Contribution à l'étude des altérations microbiennes des organes charnus des plantes". The results of the investigation set forth in this paper were recognized as a serious contribution on the subject of parasites of plants and their action in the production of putrefaction. The paper deals with many other matters too numerous to mention, but a summary of Hauman's conclusions regarding the factors which favour or hinder parasitism in plants is as follows: (1) conditions which determine the abundance or scarcity in the environment of the organs of propagation of the parasites ; (2) conditions more or less favourable in the medium for the develop. ment of the parasites; (3) conditions more or less favourable for the reception of, or resistance to, the host.

Jorge R. Christensen contributes a paper with the title "Estudio sobre el Género Diabrotica Chev. en la Argentina". The author has conducted very extensive research on the subject, and supplies a list of all the species which are pests of cultivated land, and in addition, has given indications of their hosts. The paper deals with the distribution and damage caused by the pest, its anatomy and external morphology, its life-cycle, and the method for combating it. Careful observation has shown that the most effective insecticide for dusting is rotenone, using a concentration of $0 \cdot 5-1$ per cent. Good results were also obtained by using 'Piretrina' in a 5 per cent concentration, but, on the whole, it was inferior.to rotenone. In addition to a description of new species, there are also descriptions of species studied by other authors, and thirty-two illustrations at the end of the work.

A paper by Emilio F. Paulsen and Emilio S. Lio, with the title "Sobre el Contenido de arsénico en el tabaco", deals with the determination of the arsenical contents of smoking tobacco. The arsenic serves to combat certain pests, and the plant retains and absorbs a proportion of the insecticide, the amount depending on the nature of the preparation employed and also on the method of application. Considerable differences were found in the amount of arsenic present. Thus, in the case of the black cigarettes, 10-15 parts per million were found, while the contents for Virginian cigarettes fluctuated between 
5.8 and $16 \cdot 6$ per million. In the natural tobacco on which no work had been expended before the tests were applied, the amount varied from 25 to 250 parts per million. The data refer to tobacco grown in the Argentine and worked up in its factories, with the exception of some specimens which contained mixtures of imported tobacco, and all the data refer to the types of cigars and cigarettes which find their way into the market. The danger of arsenic poisoning from tobacco, is obviously very small.

\section{MAGNETO-STRICTION NOISE FROM TELEPHONE WIRES}

$\mathrm{W}$ HEN magnetic material is subjected to a mechanical force, its magnetization is changed; and conversely, if its magnetization is changed, the material expands or contracts. There is thus a relationship between the stress and magnetization of magnetic materials which is called megnetostriction. According to an article by M. T. Dow (Bell Lab. Rec., 22, N ,. 10; June 1944), noise encountered some eight years ago on certain telephone lines was found to be caused by vibrations set up by wind in a long river-crossing consisting of steel conductors, and experiments indicated clearly that the noise was due to magneto-striction. The alternating stresses in the taut wires vibrating under the influence of wind, resulted in corresponding changes in the magnetization of the steel wires, and these magnetic fluctuations induced voltages in the wires that appeared as noise at the ends of the line.

Since the voltages induced by magneto-striction vary at rates which depend on the rates of change of stress in the wire, the noise frequencies are related to the frequencies of vibration of the wire, and these in turn are determined largely by the size of the wire and the velocity of the wind; wire tension, spanlength, and other such factors also have some effect. It was found that practically all frequencies of the magneto-striction noise were in the voice range, and under certain conditions the dominant frequency was in the neighbourhood of 1,000 cycles/second, which is the range producing the greatest disturbing effect. The test results confirmed a simple relationship expressed as $f=7(v / d)$, where $f$ is the principal noise frequency in cycles/second, $v$ is the wind velocity in m.p.h., and $d$ is the diameter of the wire in inches. To produce a 1,000-cycle noise, therefore, the wind velocity is given by the expression $v=143 d$. Commonly used copper-steel wires are of $0 \cdot 104$ in. and $0.128 \mathrm{in}$. in diameter, and for these two sizes the wind velocities to give 1,000-cycle noise are about 15 and 18 m.p.h., respectively, These are velocities commonly encountered.

For the same velocity of wind, the greatest effect is experienced when the wind is approximately at right angles to the direction of the wires. Taut wires with sags of less than 8-10 in. in $130 \mathrm{ft}$. spans favour the generation of magneto-striction noise. Fairly steady winds with velocities around 20-35 m.p.h. produce the highest values of noise. Winds in this range of velocity favour the building up of resonance, which leads to high amplitudes, and also are likely to produce frequencies of the greatest disturbing effect. Turbulent winds, with velocities up to 64 m.p.h., seem to inhibit the building up of resonance, and thus are less effective in producing noise. The effect is greatest in all-steel wires, and becomes less the greater the relative amount of copper.

An estimate based on a study of the results obtained indicates that for tight wires, in an exposure of 25 miles or more in length where conditions favour magneto-striction noise, the unamplified noise generated during windy periods would probably average around $28 \mathrm{db}$. above reference noise. Occasionally, maxima might reach as high as $36 \mathrm{db}$. above reference noise. Both these figures are for tight, copper-clad wire of 40 per cent conductivity; the corresponding figures for wire of 30 per cent conductivity would be about $3 \mathrm{~d}$ b. higher. Under similar conditions, the noise for all-steel wire is likely to be $10-25 \mathrm{db}$. higher. Actually, while magneto-striction noise has been experienced with steel wire, none has ever been reported on circuits employing copper-clad wire.

\section{USE OF 'POLAROID' FOR THE MICROSCOPE}

\author{
By DR. A. F. HALLIMOND \\ Geological Survey of Great Britain
}

$\mathrm{H}$ ILMS of very strongly pleochroic material, usually mounted between glass plates, have been available during the past few years under the trade-name 'Polaroid'. For some purposes they can replace the nicol prism, but their use has been restricted tecause in a moderately strong light they transmit a noticeable reddish-violet colour at the position of extinction.

Disks of improved 'Polaroid' of high optical quality have since been made, and a British firm of instrument makers recently placed two of them at the disposal of H.M. Geological Survey for investigation of their possible use in the petrological microscope. The following is a brief report, communicated by permission of the Director, Geological Survey and Museum, on their properties, which rival those of the best nicol prisms.

Extinction. It has been understood that 'Polaroid' was prepared by the alignment of small pleochroic crystals in an artificial preparation. Consequently one might expect that the extinction would be less sharp than that for a nicol prism, and that a small proportion of the strongly absorked ray would still be transmitted. For the pair of disks now to be described both these fears proved groundless.

Fig. I shows two examples from several curves that were measured by means of a visual microphotometer, similar in purpose to that of M. Berek, which I hope to describe shortly. One nicol (or 'Polaroid') was fixed in the usual position in the microscope, while the other was placed on the rotating stage, which could be read to $0 \cdot 1^{\circ}$. Stray light was excluded by means of black paper tubes. With a strong beam it was possible to obtain a variation of 100 units on the photometer scale within a rotation of $\pm 2^{\circ}$ from extinction. Curve $A$ is the ordinary extinction curve for two nicol prisms ; there is good agreement between the photometer readings (shown by circles) and the continuous curve calculated from the usual formula, indicating that the photometer scale is practically linear. The readings along curve $B$ were obtained with two 'Polaroids'; they again show substantial agreement with the corresponding calculated curve, even for the range nearest extinction. 